\title{
Effect of frankincense oil on the neurochemical changes induced in rat model of status epilepticus
}

\author{
Eman N. Hosny ${ }^{1 *}$, Mohamed E. Elhadidy ${ }^{2}$, Hussein G. Sawie ${ }^{1}$, Ayman Kilany ${ }^{2}$ and Yasser A. Khadrawy ${ }^{1}$
}

\begin{abstract}
Background: The current objective is to evaluate the effect of frankincense oil on the convulsions and the associated neurochemical alterations produced in pilocarpine-induced status epilepticus rat model.

Methods: Rats were divided randomly into: control, status epilepticus rat model and rat model of status epilepticus pretreated with frankincense oil daily for 5 days before pilocarpine treatment. On the fifth day, after pilocarpine injection, rats were observed to evaluate the severity of seizures for $2 \mathrm{~h}$. The oxidative stress parameters malondialdehyde, reduced glutathione and nitric oxide, the proinflammatory cytokines interleukin- 6 and interleukin$1 \beta$ and acetylcholinesterase were determined in the cortex, hippocampus and striatum. Dopamine, norepinephrine and serotonin were measured in the cortex and striatum.

Results: The status epilepticus model exhibited repetitive seizures in the form of generalized tonic- clonic convulsions after $30 \mathrm{~min}$. of pilocarpine injection. This was associated with a significant increase in the levels of malondialdehyde and nitric oxide and a significant decrease in reduced glutathione in the three regions. A significant increase was also observed in interleukin-1 $\beta$, interleukin- 6 and acetylcholinesterase. In the cortex and striatum, a significant decrease was recorded in monoamine levels. Pretreatment of rat model of status epilepticus with frankincense oil decreased the severity of seizures that appeared in the form of tremors and facial automatisms and prevented the increase in malondialdehyde, nitric oxide, interleukin- $1 \beta$, interleukin- 6 and acetylcholinesterase and the decrease in reduced glutathione induced by pilocarpine in the studied brain regions. Frankincense oil failed to restore the decreased level of cortical serotonin and dopamine. In the striatum, frankincense oil improved the levels of serotonin and norepinephrine but failed to restore the decreased dopamine levels.
\end{abstract}

Conclusion: It is clear from the present results that frankincense oil reduced the severity of seizures induced by pilocarpine. This could be mediated by its potent antioxidant and anti-inflammatory effects.

Keywords: Status epilepticus, Oxidative stress, Neuroinflammation, Monoamines, Acetylcholinesterase - rat

\section{Introduction}

Status epilepticus (SE) is a neurological emergency that represents the second most recurrent lifethreatening crisis after stroke. Its incidence is between 12 and 40 per 100,000 persons annually. Higher numbers are observed in children and elderly, generating a 'U-shaped' curve $[1,2]$. It is defined as repetitive or

\footnotetext{
* Correspondence: emannasr_30@yahoo.com

${ }^{1}$ Medical Physiology Department, National Research Centre, Giza, Egypt Full list of author information is available at the end of the article
}

ongoing seizures lasting for about 5 min with no recovery of baseline clinical conditions in between [3]. SE may be induced by various neurological disorders, including stroke, brain trauma, brain infection and brain tumor [4]. Several neurochemical changes have been detected during SE. Oxidative stress is implicated in $\mathrm{SE}[5,6]$ and the reactive oxygen species produced during SE have been considered to play a role in the mechanisms leading to glutamatergic excitotoxicity in vitro [7] and in vivo [8]. Oxidative stress may result in damage to DNA, proteins and lipids 
leading eventually to neuronal injury, gliosis and cognitive impairment [6, 9]. In addition, both clinical studies and experimental models provided evidence implicating inflammatory cytokines in the induction and propagation of seizures either directly or indirectly [10]. It has been reported that interleukin-1 beta (IL-1 $\beta$ ) could initiate and aggravate seizure activity in epileptic experimental animal models $[11,12]$. On the other hand, seizures promote the expression of IL- $1 \beta$ and the mRNA of both IL-1 $\beta$ and IL-1Ra [13]. It has been reported that (interleukin-6) IL-6 mRNA is induced rapidly in the hippocampus, cortex, dentate gyrus, amygdala and meninges after seizures, but upregulation of IL-6-receptor mRNA was confined to the hippocampus $[14,15]$. In experimentally-induced SE rodent models using electrical stimulation, bicuculline methiodide or kainic acid, IL-6 mRNA and IL6 protein showed a transient increase in glial cells which was prominent $6 \mathrm{~h}$ after SE [13].

Seizure activity induced a variety of local biochemical alterations affecting several neurotransmitters (adenosine, dopamine (DA), norepinephrine (NE), serotonin (5$\mathrm{HT}$ ), gamma-aminobutyric acid (GABA), and glutamate) [16-19] and the densities of muscarinic $\left(M_{1}+M_{2}\right)$ and dopaminergic $\left(\mathrm{D}_{2}\right)$ receptors in the striatum and hippocampus [20].

The role of acetylcholine (ACh) and DA in seizures is unclear. It has been suggested that ACh could activate limbic seizures while other neurotransmitter systems could be related to epileptogenesis [21].

Frankincense is an aromatic resin obtained from species of the Burseraceae family [22]. Previous studies described the neuroprotective, antioxidant, anti-inflammatory and anti-apoptotic properties of Boswellia serrata or its active constituents against various neurological disorders. Jalili et al. [23] reported that aqueous extract of Boswellia serrata produced a marked increase in the number of neuronal processes in the hippocampal CA1 region and improved passive-avoidance learning in pentylenetetrazolkindled rats. In addition, Moein et al. [24] suggested that Boswellia serrata might improve cognitive function in patients with diffuse axonal injury.

Although extensive efforts have been carried out to find a successful treatment for SE, 30\% of epileptic patients suffer from uncontrolled seizures [25]. Thus, SE needs immediate intervention to prevent its harm and mortality [26].

Therefore, the present study aims to evaluate the anticonvulsant effect of frankincense oil using rat model of SE induced by pilocarpine. This was carried out by investigating the effect of frankincense oil on the seizures and associated neurochemical changes; oxidative stress, neuroinflammation and monoamine levels, induced in the cortex, hippocampus and striatum by SE.

\section{Materials and methods}

\section{Animals}

Thirty male Wistar albino rats obtained from the Experimental Animal Centre (National Research Centre), weighing 160-180 g, were used in the present study. All animals were housed in stainless steel cages with ad libitum access to standard laboratory rodent chow and tap water. They were placed in a temperature-controlled $\left(20-25^{\circ} \mathrm{C}\right)$ and artificially illuminated $(12 \mathrm{~h}$ dark/light cycle) room free of any chemical contamination. Animal procedures were approved by the Ethics Committee of the National Research Centre and were performed in compliance with the recommendations of the National Institutes of Health Guide for Care and Use of Laboratory Animals (publication no. 85-23, revised 1985).

\section{Chemical and drugs}

Pilocarpine chloride was obtained from Sigma. It was dissolved in saline. Atropine sulfate was obtained from Boehringer Ingelheim (Germany). Frankincense oil of Boswellia serrata was purchased from Harraz Herbal Drugstore in Cairo, Egypt.

\section{Gas chromatography/ mass spectrometry (GC/MS) analysis}

The GC/MS analysis of the oil was carried out using Shimadzu GC-MS, Model QP-2010 Ultra, equipped with head space AOC-5000 auto injector and a Rtx-5 MS fused-silica column of $30 \mathrm{~m}$ in length, $0.25 \mathrm{~mm}$ ID, $0.25 \mu \mathrm{m}$ film thickness (cross bond 5\% diphenyl/95\% dimethyl polysiloxane) with helium as carrier gas at a flow rate of $0.99 \mathrm{ml} / \mathrm{min}$. The gas chromatograph was coupled to a QP2010 ultra mass spectrometer (MS) detector. The sample was injected in $5 \mu \mathrm{l}$ volume in splitless mode. The temperature was programmed initially at $40^{\circ} \mathrm{C}$ for $2 \mathrm{~min}$, and then increased with a rate of $5^{\circ} \mathrm{C} /$ min up to $210^{\circ} \mathrm{C}$. Bioactive compounds of frankincense oil were identified according to the GC retention time on HP-MS column and matching of the spectra with computer software data of standards. The spectrum of the unknown compound was compared with the spectrum of the known compounds.

\section{Experimental model}

Animals were divided randomly into three groups (10 rats each). Control group received a daily intraperitoneal injection of saline for 5 consecutive days. The second group represents the rat model of status epilepticus (SE) in which rats received a daily oral administration of saline for five days before the induction of SE by the intraperitoneal injection (i.p.) of a single dose of pilocarpine (300 mg/kg) according to Turski et al. [27]. Atropine sulfate was injected subcutaneously at a dose of $5 \mathrm{mg} / \mathrm{kg}$, $30 \mathrm{~min}$ after the last saline administration before the 
induction of SE, to prevent peripheral muscarinic stimulation [28]. After about $30 \mathrm{~min}$ of pilocarpine injection, the animals became hypoactive and then displayed orofacial movements, salivation, eye-blinking, twitching of vibrissae, and yawning; generalized convulsions and limbic SE developed about 40-60 min after the injection [29]. The animals of the third group received a daily oral administration of frankincense oil $(1000 \mathrm{mg} / \mathrm{kg})$ by gavage [30] for five consecutive days prior to atropine and pilocarpine administration. The rats of the third group showed normal activity and did not exhibit any convulsions or limbic seizures. In addition, the oro-facial movements, salivation, eye-blinking, twitching of vibrissae, and yawning decreased greatly.

\section{Preparation of samples}

After $2 \mathrm{~h}$ of pilocarpine injection, all animals were sacrificed by sudden decapitation. The brain of each rat was removed quickly and transferred rapidly to an ice-cold Petri dish where it was divided into two halves right and left. Each half was dissected to obtain cortex, striatum and hippocampus. Each brain area was weighed and frozen at $-80^{\circ} \mathrm{C}$ until analyzed. The hippocampus and the right half of each cortex and striatum were homogenized in Tris- $\mathrm{HCl}$ buffer ( $\mathrm{pH}$ 7.4) and used for the determination of oxidative stress parameters, acetylcholinesterase, IL-1 $\beta$ and IL-6. The left half of each cortex and striatum was homogenized in an ice-cold solution of acidified $n$ butanol and used for monoamines analysis.

\section{Determination of lipid peroxidation}

Lipid peroxidation was assayed by measuring the levels of malondialdehyde (MDA) in the brain tissues. MDA was determined by measuring thiobarbituric reactive species using the method of Ruiz-Larrea et al. [31] in which the thiobarbituric acid reactive substances react with thiobarbituric acid to produce a pink colored complex whose absorbance is read at $532 \mathrm{~nm}$.

\section{Determination of nitric oxide}

Nitric oxide (NO) was determined spectrophotometrically in the brain tissue according to the method described by Montgomery and Dymock [32]. This method depends on the measurement of endogenous nitrite concentration as an indicator of nitric oxide production. The resulting azo dye has a bright reddish-purple color whose absorbance is read at $540 \mathrm{~nm}$.

\section{Determination of reduced glutathione}

The assay of reduced glutathione (GSH) levels was performed according to the spectrophotometric method of Beutler et al. [33]. It depends on the reduction of 5,5' dithiobis-2-nitrobenzoic acid (DTNB) with glutathione to produce a yellow compound, the absorbance of which is measured at $412 \mathrm{~nm}$. The reduced chromogen is directly proportional to GSH concentration. Total GSH content was expressed in $\mathrm{mmol} / \mathrm{g}$ brain tissue.

\section{Determination of interleukin-1 $\beta$}

Interleukin-1 $\beta$ (IL-1 $\beta$ ) was measured in selected brain areas using rat ELISA Kit supplied by Glory Science Co., Ltd. (USA). The developed color was read at $450 \mathrm{~nm}$ using a microtiter plate reader. The concentration was then calculated from a standard curve. The concentration of IL-1 $\beta$ was expressed in $\mathrm{pg} / \mathrm{g}$ brain tissue.

\section{Determination of Interleukin-6}

Estimation of Interleukin-6 (IL-6) levels in the cortex, hippocampus and striatum was carried out using rat ELISA Kit obtained from Glory Science Co., Ltd. (USA). The developed color was read at $450 \mathrm{~nm}$. The concentration of IL-6 was expressed in pg/g of brain tissue.

\section{Determination of acetylcholinesterase activity}

The procedure used for the determination of acetylcholinesterase (AchE) activity in selected brain areas was a modification of the method of Ellman et al. [34] as described by Gorun et al. [35]. The principle of the method is the measurement of the thiocholine produced as acetylthiocholine is hydrolyzed. The color was read immediately at $412 \mathrm{~nm}$. The results were expressed as $\mu \mathrm{mol} \mathrm{SH} / \mathrm{min} / \mathrm{g}$ brain tissue.

\section{Determination of monoamines concentrations}

The quantitative determination of serotonin (5-HT), norepinephrine (NE) and dopamine (DA) levels in the cortex and striatum was carried out according to the method of Ciarlone [36] using a spectrofluorometer (Jasco FP-6500, JASCO Ltd., Tokyo, Japan) with a source of xenon arc lamp $150 \mathrm{~W}$ (excitation slit band width of excitation monochromator: $5 \mathrm{~nm}$, and emission slit band width of emission monochromator: $5 \mathrm{~nm}$ ).

\section{Statistical analysis}

All results were expressed as means \pm S.E.M. Statistical differences between the groups under investigation were tested by one-way analysis of variance (ANOVA) followed by Duncan as post hoc test. The difference was considered significant at $p$-value $\leq 0.05$. Statistical Package for Social Sciences (SPSS) software (version 16) was used for all statistical comparisons.

\section{Results}

\section{Results of GC/MS analysis}

Gas chromatography mass spectrometric $(\mathrm{GC} / \mathrm{MC})$ analysis showed that the main components of frankincense oil were octyl acetate (67.44\%), thymol (16.69\%), octanol (10.1\%) and carvone (2.96\%). In addition, other constituents of low 
percentage have been detected such as hexyl caproate $(0.75 \%)$, heptanoic acid octyl ester $(0.49 \%)$, lauryl acetate $(0.46 \%), 1,8$-cineole $(0.33 \%)$ and cymene $(32 \%)$. This was in agreement with Al-Yasiry and Kiczorowska who demonstrated that the major constituent of frankincense oil was octyl acetate [37] (Table 1, Fig. 1).

\section{Oxidative stress parameters}

As illustrated in Table 2, induction of SE by pilocarpine injection significantly increased the levels of MDA (+ $42.34 \%,+578.66 \%$ and $+138.51 \%)$ and $\mathrm{NO}(+25 \%$, + $100 \%$ and $+138.51 \%)$ in the cortex, hippocampus and striatum, respectively, as compared to control group. This was associated with a significant decrease in GSH levels in the cortex, hippocampus and striatum recording $-14.38 \%,-16.43 \%$ and $-13.83 \%$, respectively, below the control values. Protection of SE rats with frankincense oil succeeded in normalizing the levels of MDA, NO and GSH in the selected brain areas.

\section{Interleukin-1 $\beta$ (IL-1 $\beta$ ) and IL-6}

As shown in Fig. 2, SE rat model demonstrated a significant increase in the cortical, hippocampal and striatal IL-1 $\beta(+22.84 \%,+50 \%$ and $+41.18 \%$, respectively $)$ and IL-6 (+ 20.69\%, + 18.42 and $+22.73 \%$, respectively) levels above the control values. The protection of rat model with frankincense oil prevented the increase in IL-1 $\beta$ and IL-6 levels in the cortex, hippocampus and striatum.

\section{Acetylcholinesterase activity}

Acetylcholinesterase (AchE) activity increased significantly in the cortex, hippocampus and striatum of SE-induced rats recording $+106.17 \%,+63.20 \%$ and $+41.51 \%$, respectively, above the control values. The increased striatal AchE activity was improved in frankincense oil-protected group. Also, protection with frankincense oil prevented the increase in AchE activity induced by pilocarpine injection in the cortex and hippocampus of SE rat model (Fig. 3).

Table 1 GC/MC analysis of frankincense oil derived from Boswellia serrata

\begin{tabular}{llll}
\hline Peak & Retention time & Constituent name & \% Area \\
\hline 1 & 9.301 & cymene & 0.32 \\
2 & 9.652 & 1,8-Cineole & 0.33 \\
3 & 11.673 & Octanol & 10.10 \\
4 & 14.200 & n-Octyl methanoate & 0.45 \\
5 & 18.150 & Octyl acetate & 67.44 \\
6 & 22.442 & Thymol & 16.69 \\
7 & 22.825 & Carvacrol & 2.96 \\
8 & 27.025 & Lauryl acetate & 0.46 \\
9 & 33.943 & Hexyl caproate & 0.75 \\
10 & 37.591 & Heptanoic acid, octyl ester & 0.49 \\
\hline
\end{tabular}

\section{Monoamine neurotransmitters}

In rat model of SE, cortical 5-HT and DA levels decreased significantly by $19.44 \%$ and $23.20 \%$, respectively, below the control value. However, cortical NE did not show any significant change as compared to control. Protection with frankincense oil improved the significant decrease in cortical DA $(-15.47 \%)$ induced by pilocarpine injection without preventing the decrease recorded in cortical 5-HT. However, the percentage difference from the control of cortical 5-HT was improved from $19.44 \%$ to $-14.12 \%$ (Table 3 ).

Moreover, statistical analysis revealed a significant decrease in striatal 5-HT $(-34.48 \%), \mathrm{NE}(-29.17 \%)$ and DA $(-19.32 \%)$ levels in SE rat model below the control values. The protection of SE rat model with frankincense oil prevented the recorded decrease in striatal 5-HT and $\mathrm{NE}$ levels but failed to prevent the significant decrease in striatal DA recording $-23.78 \%$ as compared to control values (Table 3 ).

\section{Discussion}

The present study was carried out to investigate the anticonvulsant effect of frankincense oil in SE rat model induced by pilocarpine. In the present study, a state of repetitive tonic-clonic convulsions was observed after 30 min of pilocarpine injection and persisted till rats were sacrificed. This behavior, which reflects a state of cerebral hyperexcitability, was associated with a state of oxidative stress in the cortex, hippocampus and striatum. This was clear from the significantly increased levels of lipid peroxidation and nitric oxide and the decreased level of reduced glutathione in the three studied brain regions.

It has been reported that oxidative stress may contribute to the development of seizures [38]. On the other hand, it has been reported that recurrent seizures increase the reactive oxygen species (ROS) in the brain inducing oxidative stress. This is considered one of the mechanisms that could independently contribute to the disease progression leading eventually to neuronal injury [39].

Oxidative stress is particularly accelerated in the brain due to the abundance of oxidizable lipids and metals, and shortage of antioxidant mechanisms than other tissues [40]. Another factor that could exacerbate the oxidative stress is the high metabolic rate of the brain that increases during seizures [41]. This makes the cerebral blood flow and oxygen supply insufficient to fulfill the tissue needs during the exacerbated metabolic rate [42].

Lipid peroxidation represents an indicator of irreversible neuronal damage and has been implicated as a possible mechanism underlying epileptogenesis [29]. During $\mathrm{SE}$, excessive release and accumulation of the excitatory 


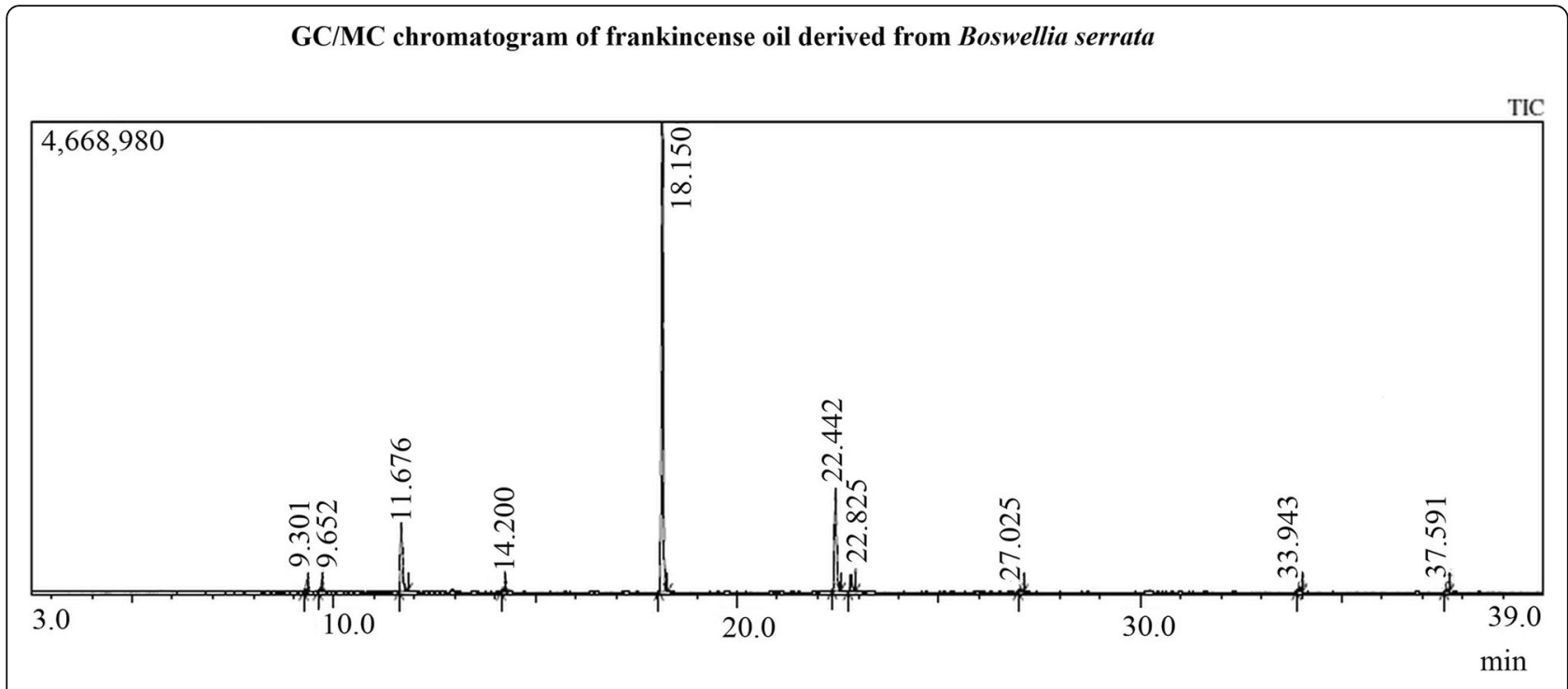

Figure 1

Fig. 1 Chromatogram of frankincense oil fractionation by GC/MC

neurotransmitter glutamate over-activates N-methylD-aspartate (NMDA) glutamate receptors. Overactivation of NMDA receptor causes massive $\mathrm{Ca}^{2+}$ influx, which in turn results in overproduction of free radicals, nitric oxide, mitochondrial dysfunction, lipid peroxidation and activation of caspases [43]. This phenomenon is known as excitotoxicity [44]. The generated free radicals can attack phospholipids in cell membrane resulting in increased lipid peroxidation levels [45]. Therefore, the increase in lipid peroxidation in the cortex, hippocampus and striatum recorded in the present study could be ascribed to the excitotoxicity induced by enhanced excitatory neurotransmission.

Table 2 The Effect of daily pretreatment with frankincense oil $(1000 \mathrm{mg} / \mathrm{kg} /$ day for 5 days) on the levels of malondialdehyde (MDA), nitric oxide (NO), and reduced glutathione (GSH) in the cortex, hippocampus and striatum of rat model of SE

\begin{tabular}{|c|c|c|c|c|c|c|c|}
\hline & & Control & Rat model of SE. & $\% \mathrm{D}$ & Oil protected & $\% \mathrm{D}$ & $p$-value \\
\hline \multirow[t]{3}{*}{ Cortex } & $\begin{array}{l}\text { MDA } \\
(\mathrm{nmol} / \mathrm{g})\end{array}$ & $7.51^{a} \pm 0.47$ & $10.69^{\mathbf{b}} \pm 1.08$ & +42.34 & $5.36^{\mathbf{a}} \pm 0.67(8)$ & -28.63 & 0.000 \\
\hline & $\begin{array}{l}\mathrm{NO} \\
(\mu \mathrm{mol} / \mathrm{g})\end{array}$ & $0.04^{\mathbf{a}} \pm 0.002$ & $0.05^{\mathbf{b}} \pm 0.005(7)$ & +25 & $0.03^{\mathbf{a}} \pm 0.002$ & -25 & 0.013 \\
\hline & $\begin{array}{l}\text { GSH } \\
(\mathrm{mmol} / \mathrm{g})\end{array}$ & $4.38^{\mathbf{a}} \pm 0.12(7)$ & $3.75^{\mathbf{b}} \pm 0.03(6)$ & -14.38 & $4.74^{a} \pm 0.23(8)$ & +8.22 & 0.002 \\
\hline \multirow[t]{3}{*}{ Hippocampus } & $\begin{array}{l}\text { MDA } \\
(\mathrm{nmol} / \mathrm{g})\end{array}$ & $2.53^{a} \pm 0.28(7)$ & $17.17^{\mathbf{b}} \pm 2.27(8)$ & +578.66 & $6.62^{\mathbf{a}} \pm 1.40(7)$ & +161.66 & 0.000 \\
\hline & $\begin{array}{l}\mathrm{NO} \\
(\mu \mathrm{mol} / \mathrm{g})\end{array}$ & $0.12^{\mathrm{a}} \pm 0.01$ & $0.24^{\mathbf{b}} \pm 0.01$ & +100 & $0.15^{\mathbf{a}} \pm 0.02$ & +25 & 0.000 \\
\hline & $\begin{array}{l}\text { GSH } \\
(\mathrm{mmol} / \mathrm{g})\end{array}$ & $12.60^{\mathrm{a}} \pm 0.50(7)$ & $10.53^{\mathbf{b}} \pm 0.07(7)$ & -16.43 & $12.47^{\mathrm{a}} \pm 0.54(8)$ & -1.03 & 0.006 \\
\hline \multirow[t]{3}{*}{ Striatum } & $\begin{array}{l}\text { MDA } \\
(\mathrm{nmol} / \mathrm{g})\end{array}$ & $1.61^{\mathrm{a}} \pm 0.25$ & $3.84^{\mathbf{b}} \pm 0.90(9)$ & +138.51 & $1.66^{\mathbf{a}} \pm 0.24(9)$ & +3.11 & 0.016 \\
\hline & $\begin{array}{l}\mathrm{NO} \\
(\mu \mathrm{mol} / \mathrm{g})\end{array}$ & $0.11^{\mathbf{a}} \pm 0.01$ & $0.15^{\mathbf{b}} \pm 0.02(7)$ & +36.36 & $0.09^{\mathbf{a b}} \pm 0.01$ & -18.18 & 0.003 \\
\hline & $\begin{array}{l}\text { GSH } \\
(\mathrm{mmol} / \mathrm{g})\end{array}$ & $15.62^{\mathbf{a}} \pm 0.74(6)$ & $13.46^{\mathbf{b}} \pm 0.39(7)$ & -13.83 & $16.04^{\mathbf{a}} \pm 0.44$ & +2.69 & 0.004 \\
\hline
\end{tabular}

Values represent mean \pm S.E. with the number of animals between parentheses

$\%$ D: \% difference with respect to control values

Different letters indicate significantly different means at $p$-value $<0.05$

Same letters indicate non significant changes 

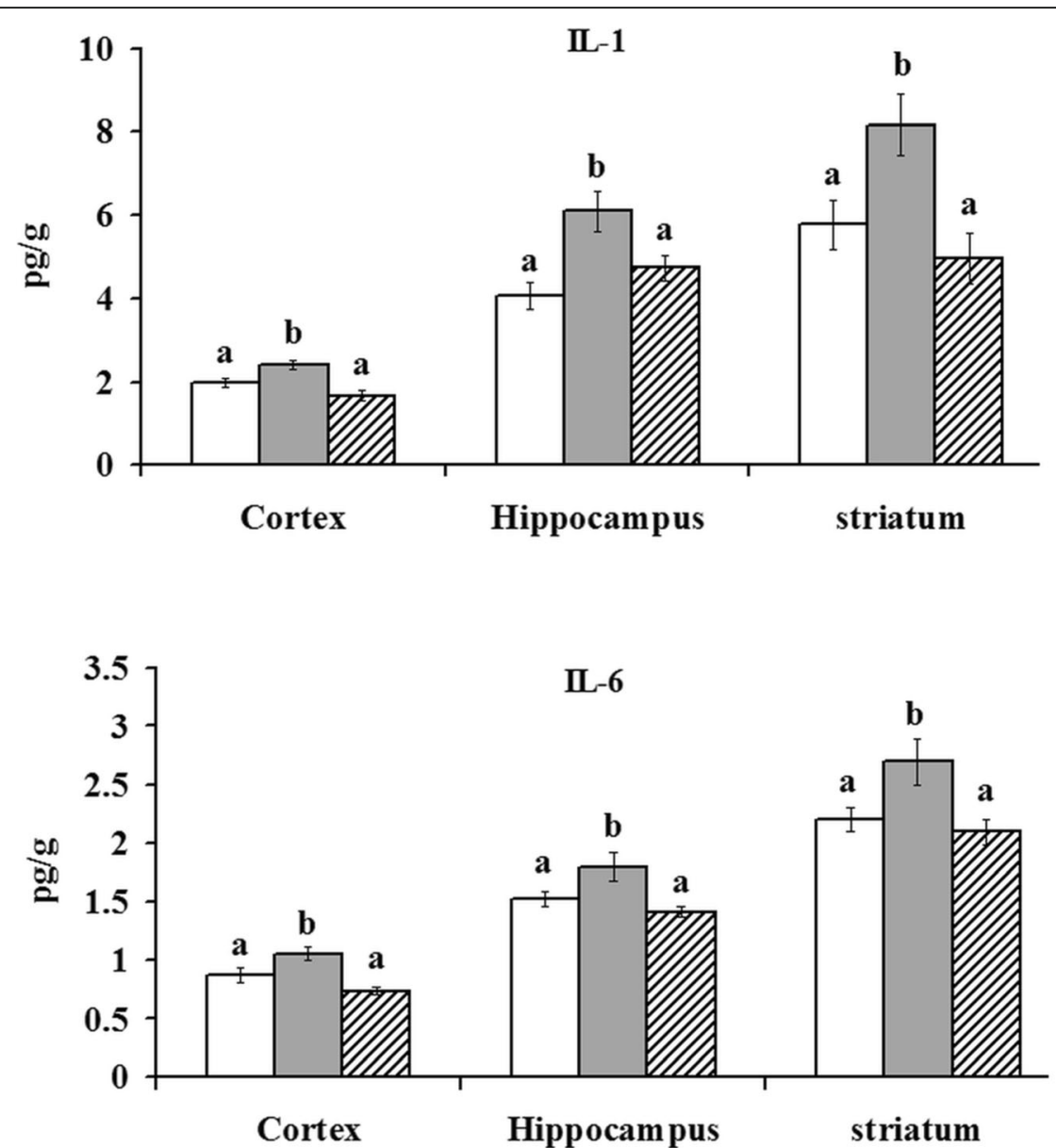

Fig. 2 The Effect of daily protection with frankincense oil (1000 mg/kg/day for 5 days) on the levels of Interleukin-1 (IL-1 $\beta$ ) and Interleukin-6 (IL6) in the cortex, hippocampus and striatum in rat model of status epilepticus (SE). $\square$ Control $\square$ Rat model of SE. $\square$ Oil protected group. Statistically significant means ( $p$-value $<0.05$ ) are given different letters and same letters indicate non significant changes

The present increase in NO levels in the three studied brain regions by pilocarpine may be due to the stimulation of nitric oxide synthase by the massive influx of calcium as a consequence of excitotoxicity. The increased level of NO may interact with singlet oxygen and produce the most reactive and damaging molecule peroxynitrite. This explanation is supported by the studies of Gupta and Dettbarn [46] and Kato et al. [47] who found that NO formation increased during seizures due to the $\mathrm{Ca}^{2+}$-dependent enhancement of endothelial (eNOS) and neuronal (nNOS) NO synthases, as reported after kainic acid- and pentylenetetrazole-induced seizures. In addition, alteration in nitric oxide metabolism, and increase in its metabolites (nitrite and nitrate) have been observed after pilocarpine-induced seizures. NO metabolites may interact with glutamate receptors and stimulate the central nervous system $[48,49]$. On the other hand, the increase in NO may play a role in increasing the blood flow to supply the brain with the increased requirements from glucose and oxygen during the increased metabolic rate [50].

Reduced glutathione (GSH) is a free radical scavenging agent. The present depletion of GSH in the cortex, hippocampus and striatum may be due to the produced free radicals during SE.

It is evident from the present study that oxidative stress may be a causative factor or resultant of SE. Therefore, antioxidants may play a crucial role in breaking this vicious cycle.

The present recorded increases in the levels of the pro-inflammatory cytokines IL- $1 \beta$ and IL- 6 in the cortex, hippocampus and striatum represent an indicator of the induced neuroinflammation during SE. Different degrees of inflammation have been reported to accompany the various risk factors that induce epilepsy such as tumors, traumas, and infections in the brain, and are associated with recurrent seizures [51]. Similarly, it has been proposed that inflammatory mediators participate in the development of seizures [52]. Thus, it may be possible to 


\section{$\operatorname{AchE}$}

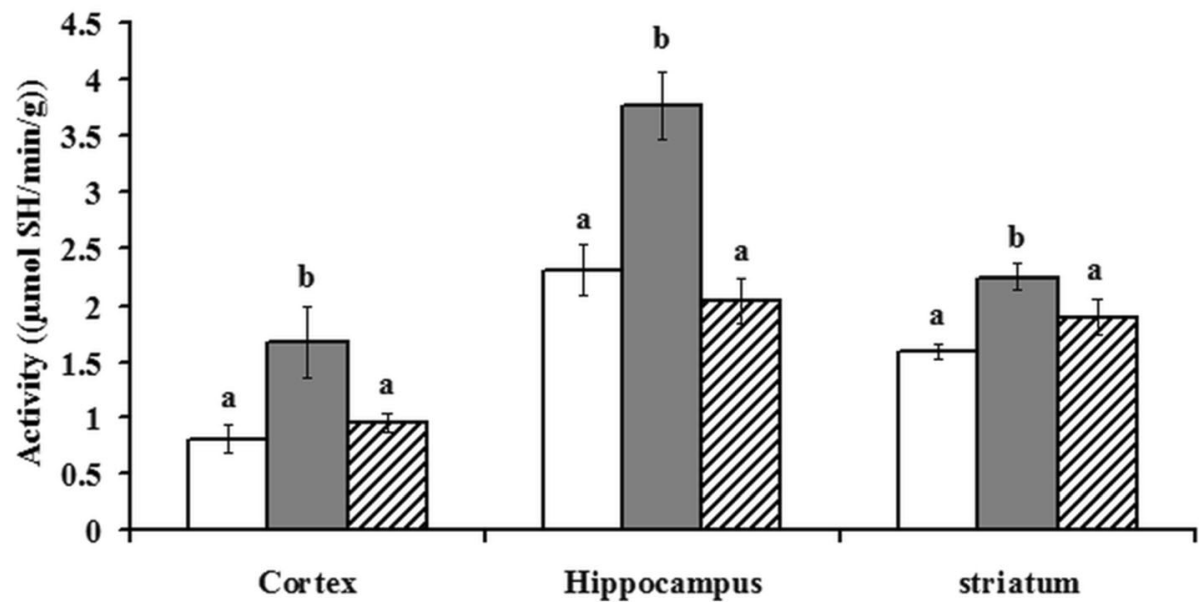

Fig. 3 The Effect of daily protection with frankincense oil $(1000 \mathrm{mg} / \mathrm{kg} /$ day for 5 days) on the activity of acetylcholinesterase (AchE) in the cortex, hippocampus and striatum in rat model of status epilepticus (SE). $\square$ Control $\square$ Rat model of SE. $\square$ Oil protected group. Statistically significant means $(p$-value $<0.05)$ are given different letters and same letters indicate non significant changes

control seizures by altering inflammatory mediator signaling in the brain [53].

The present increase in IL-1 $\beta$ and IL-6 could be attributed to the activation of microglia and astrocytes that release large amounts of pro-inflammatory mediators inducing neuroinflammation through a variety of signaling pathways. IL- $1 \beta$ directly modulates ion channels, enhancing NMDA and AMPA receptors $[54,55]$ and reducing the effectiveness of gammaaminobutyric acid type A (GABA-A) receptors [56], which can change the excitability of neurons. The inflammation can enhance excitability through sprouting, neurogenesis and neuronal damage, leading eventually to SE [57].
Acetylcholine (Ach) is the second most prevalent excitatory neurotransmitter (after glutamate) in the brain. It has been found that ACh content increased in the cortex and hippocampus during $\mathrm{SE}$ with increased ACh efflux into the cortical cup [58, 59]. Therefore, the present increase in AchE activity in the studied brain regions of rat model of SE may be a compensatory mechanism to slow down the hypercholinergic activity, as AchE acts to breakdown Ach to terminate its effect at its receptors.

Dopamine [60], NE [61], 5-HT [62] and histamine [63] were all shown to stop seizure activity. Another proof for the involvement of monoamines in epileptogenesis is the evidence that bipolar disorders, depression, and other

Table 3 The Effect of daily pretreatment with frankincense oil ( $1000 \mathrm{mg} / \mathrm{kg} /$ day for 5 days) on the levels of serotonin (5-HT), norepinephrine (NE) and dopamine (DA) in the cortex and striatum in rat model of SE

\begin{tabular}{|c|c|c|c|c|c|c|c|}
\hline & & Control & Rat model of SE. & $\% \mathrm{D}$ & Oil protected & $\% \mathrm{D}$ & $p$-value \\
\hline \multirow[t]{3}{*}{ Cortex } & $\begin{array}{l}5-\mathrm{HT} \\
(\mu \mathrm{g} / \mathrm{g})\end{array}$ & $4.32^{\mathrm{a}} \pm 0.09$ (8) & $3.48^{\mathbf{b}} \pm 0.11(7)$ & -19.44 & $3.71^{\mathbf{b}} \pm 0.22(7)$ & -14.12 & 0.002 \\
\hline & $\begin{array}{l}N E \\
(\mu g / g)\end{array}$ & $0.34^{\mathbf{a}} \pm 0.01$ & $0.34^{\mathrm{a}} \pm 0.01(6)$ & 0 & $0.32^{\mathbf{a}} \pm 0.01$ & -5.88 & 0.147 \\
\hline & $\begin{array}{l}\text { DA } \\
(\mu \mathrm{g} / \mathrm{g})\end{array}$ & $1.81^{a} \pm 0.12(8)$ & $1.39^{\mathbf{b}} \pm 0.04(7)$ & -23.20 & $1.53^{\mathbf{a b}} \pm 0.10(7)$ & -15.47 & 0.015 \\
\hline \multirow[t]{3}{*}{ Striatum } & $\begin{array}{l}5-\mathrm{HT} \\
(\mu \mathrm{g} / \mathrm{g})\end{array}$ & $11.31^{a} \pm 0.81$ & $7.41^{\mathbf{b}} \pm 0.61(7)$ & -34.48 & $9.67^{a} \pm 0.62(8)$ & -14.50 & 0.003 \\
\hline & $\begin{array}{l}N E \\
(\mu g / g)\end{array}$ & $0.96^{a} \pm 0.07$ & $0.68^{\mathbf{b}} \pm 0.04(7)$ & -29.17 & $0.91^{\mathbf{a}} \pm 0.09(6)$ & -5.21 & 0.014 \\
\hline & $\begin{array}{l}\text { DA } \\
(\mu g / g)\end{array}$ & $4.71^{\mathrm{a}} \pm 0.17(7)$ & $3.80^{\mathbf{b}} \pm 0.15$ & -19.32 & $3.59^{\mathbf{b}} \pm 0.16$ & -23.78 & 0.000 \\
\hline
\end{tabular}

Values represent mean \pm S.E. with the number of animals between parentheses

$\%$ D: \% difference with respect to control values

Different letters indicate significantly different means at $p$-value $<0.05$

Same letters indicate non significant changes 
neuropsychiatric disorders involving monoaminergic impairment may increase the risk of seizure development and/or vice versa. Freitas et al. demonstrated a significant decrease in striatal DA and 5-HT during SE. The authors suggested that cholinergic activation can integrate with the dopaminergic and serotonergic systems in the acute phase of the convulsive process in rat mature striatum [17]. Accordingly, the present decrease in DA and 5-HT in the cortex and striatum of SE rat model not only explains the depressive disorder associated with epilepsy but may also have a role in the pathogenesis of convulsions induced by pilocarpine. Moreover, the present decrease in monoamine may be due to their oxidative catabolism which represents one of the sources of free radical production. Spontaneous oxidation of monoamines, particularly DA and NE in the cytoplasm may lead to the damage of cellular structures [64]. This may in part explain the oxidative stress induced during SE.

The role of ascending dopaminergic fibers from substantia nigra pars compacta to the striatum in controlling cholinergic activity by reducing Ach release is well established [65]. The depletion of DA prevents Ach release autoinhibition mediated by muscarinic autoreceptors, and this leads to excessive Ach release eventually reducing spines of the indirect pathway projection neurons in the striatum and disrupting information coming from motor control centers in the cerebral cortex [66]. Therefore, the striatal hypercholinergic activity could be mediated by the decreased level of DA. This in turn may explain the increase in motor activity in SE.

The present pretreatment of rat model of SE with frankincense oil for 5 days resulted in a reduction in the severity of seizures that occurred after $30 \mathrm{~min}$ of pilocarpine injection. Seizures appeared in the form of tremors and facial automatisms. However, frankincense oil failed to dampen the seizures completely or reduce their frequency.

The present findings showed that frankincense oil prevented the increase in lipid peroxidation and NO levels and the decrease in GSH level induced by pilcarpine in the studied brain regions. In addition, the oil ameliorated the increased levels of IL-1 $\beta$ and IL-6.

It is obvious from the present data that frankincense oil possesses powerful antioxidant and anti-inflammatory effects. The present GC/MC analysis indicates that the oil contains a high percentage of active ingredients such as octyl acetate, thymol, carvacrol and octanol in addition to other components of low percentage.

It has been reported that the antioxidant activity of frankincense oil could be attributed to its content of esters such as octyl acetate [67]. On the other hand, several studies demonstrated the antioxidant activity of essential oils containing thymol $[68,69]$. It has been suggested that thymol has an effective free radical scavenging activity which mediates its neuroprotective effect in cortical neurons [70, 71]. The antioxidant activity of thymol is attributed to the pharmacophore of the thymol phenolic hydroxyl group present in its chemical structure. The compounds characterized by the presence of phenolic groups are known to provide protection against the adverse effects of free radicals both by absorption or neutralization of free radicals and by augmentation of endogenous antioxidants [72].

Another mechanism by which thymol could exert its anti-seizure effect is its ability to block neuronal $\mathrm{Na}^{+}$ channels [73] and modulate GABA-A receptors, leading to increased flux of chloride ions into neurons [70]. Thymol also increases chloride channel activity found in oocyte and cell lines that express GABA-A receptor subunits [74]. In another study, thymol exhibited significant anticonvulsant and antiepileptogenic actions as evident from the significant decrease in seizure score and malondialdehyde levels, and increase in glutathione in pentylenetetrazole-induced kindling model [75].

The anti-inflammatory effect of thymol [76] may underlie the anti-inflammatory effect of frankincense oil in the studied brain regions. It has been reported that thymol treatment significantly reduced the release and activation of proinflammatory cytokines as evident from their reduced levels in brain tissues of rats challenged with rotenone. In addition, thymol treatment resulted in a significant decrease in the number of activated astrocytes and microglia in the striatum of rotenoneinjected animals [77]. Thus, the present reduced level of NO induced by frankincense oil in SE rats may be explained by the reduction in the number of activated glial cells, which express inducible nitric oxide synthase (iNOS) [78].

The second important component in frankincense oil that may ameliorate the neurochemical changes induced by pilocarine is carvacrol. Carvacrol possesses potent antioxidant properties [79]. The study conducted by Khalil et al. demonstrated that carvacrol prevented the early recurrence of SE, SE-induced neuronal damage and cognitive dysfunction by inhibiting transient receptor potential cation channel, subfamily $M$, member 7 (TRPM7) channels [80]. Several studies have revealed that carvacrol possesses anti-inflammatory properties $[81,82]$, which depend on its ability to decrease the generation of inflammatory mediators, as IL- $1 \beta$ and prostanoids [83].

It has been reported that thymol and carvacrol could be used as inhibitors of acetylcholinesterase (AchE) [84]. It is interesting that carvacrol was 10 times more potent than its isomer thymol in AchE inhibitory effect [85]. Therefore, the present inhibitory effect of frankincense oil on the increased AchE 
activity induced by pilocarpine may be mediated by carvacrol and thymol. Unfortunately, this may activate the cholinergic activity which may explain the inability of frankincense oil to prevent seizures in the present study.

Another component in frankincense oil that could play a role in ameliorating the changes induced by SE is octanol. It was shown that octanol reduced seizure induction and seizure discharges when it was applied directly onto the epileptic focus found in the somatosensory cortex [86]. Moreover, the intracerebroventricular (icv) administration of octanol induced a significant decrease in the amplitude and frequency of epileptiform spikes, and the epileptic behavioral score resulting from icv penicillin administration [87].

The present findings showed that frankincense oil failed to restore the decrease in cortical 5-HT and DA induced by pilocarpine. However, in the striatum, it restored 5-HT and NE to non significant changes as compared to control. These data indicate that the effect of frankincense oil on monoamine neurotransmitters was area-specific. The decreased striatal DA level induced by frankincense oil may be beneficial in reducing the hypercholinergic activity in this brain region. In the striatum, the ascending nigrostriatal dopaminergic pathway acts to control cholinergic activity which is responsible for many of the motor disorders such as tremors and stereotyped movements characterizing seizures [20]. In addition, the decrease in DA levels may be a compensatory mechanism for the hypercholinergic activity arising from the reduced AchE activity induced by frankincense oil.

The other ingredients that have been detected in frankincense oil in low percentage include cymene which has an antioxidant activity in vivo and may be used as a neuroprotective agent in the brain [88]. In addition, 1,8-ceneole has a stimulating effect on cognitive function and memory [89].

\section{Conclusion}

The present data demonstrate that frankincense oil is rich in active ingredients which exhibit potent antioxidant, anti-inflammatory, anti-seizure and partial anti-depressant effects. Thus, it could ameliorate the neurochemical changes induced during SE and halt epileptogenesis.

\section{Acknowledgements \\ Not applicable. \\ Informed consent \\ Not applicable.}

\section{Authors' contributions}

$\mathrm{EH}$ and $\mathrm{YK}$ suggested the idea and induced the rat model of status epilepticus. EH, HS, ME and YK observed and recorded the behavioral changes and carried out the neurochemical analyses. AK and ME carried out the statistical analyses. EH and YK contributed to writing the manuscript.. All authors have read and approved the final manuscript.

\section{Funding}

No funding was obtained.

\section{Ethics approval}

Animal procedures were approved by the Ethics Committee of the National Research Centre and were performed in compliance with the

recommendations of the National Institutes of Health Guide for Care and Use of Laboratory Animals (publication no. 85-23, revised 1985).

\section{Competing interests}

The authors declare that they have no competing interest.

\section{Author details}

${ }^{1}$ Medical Physiology Department, National Research Centre, Giza, Egypt.

${ }^{2}$ Department of Research on Children with Special Needs, Giza, Egypt.

Received: 23 August 2019 Accepted: 11 December 2019

Published online: 03 January 2020

References

1. DeLorenzo RJ, Hauser WA, Towne AR, Boggs JG, Pellock JM, Penberthy L, Garnett L, Fortner CA, Ko D. A prospective, population-based epidemiologic study of status epilepticus in Richmond, Virginia. Neurology. 1996;46:1029-35.

2. Dham BS, Hunter K, Rincon F. The epidemiology of status epilepticus in the United States. Neurocrit Care. 2014;20:476-83.

3. Lowenstein DH. Status epilepticus: an overview of the clinical problem. Epilepsia. 1999;40:S3-8.

4. Trinka E, Kälviäinen R. 25 years of advances in the definition, classification and treatment of status epilepticus. Seizure. 2017:44:65-73.

5. Liang LP, Ho YS, Patel M. Mitochondrial superoxide production in kainateinduced hippocampal damage. Neuroscience. 2000;101:563-70.

6. Pearson JN, Rowley S, Liang L-P, White AM, Day BJ, Patel M. Reactive oxygen species mediate cognitive deficits in experimental temporal lobe epilepsy. Neurobiol Dis. 2015;82:289-97.

7. Bonfoco E, Krainic D, Ankarcrona M, Nocotera P, Lipton AS. Apoptosis and necrosis: two distinct events induced, respectively, by mild and intense insults with Nmethyl- $d$-aspartate or nitric oxide/superoxide in cortical cell cultures. Proc Natl Acad Sci U S A. 1992;92:7162-6.

8. Shulz JN, Henshaw DR, Siwek D, Jenkins BG, Ferrante RJ, Cipolloni PB, Kowal NW, Rosen BR, Beal MF. Involvement of free radicals in excitotoxicity in vivo. J Neurochem. 1995;64:2239-47.

9. Patel M. Mitochondrial dysfunction and oxidative stress: cause and consequence of epileptic seizures. Free Radic Biol Med. 2004;37:1951-62.

10. Webster KM, Sun M, Crack P, O'Brien TJ, Shultz SR, Semple BD. Inflammation in epileptogenesis after traumatic brain injury. J Neuroinflammation. 2017; 14:10. https://doi.org/10.1186/s12974-016-0786-1

11. Vezzani A, Conti M, De Luigi A, Ravizza T, Moneta D, Marchesi F, De Simoni MG. Interleukin-1 beta immunoreactivity and microglia are enhanced in the rat hippocampus by focal kainate application: functional evidence for enhancement of electrographic seizures. J Neurosci. 1999;19:5054-65.

12. Dube C, Vezzani A, Behrens M, Bartfai T, Baram TZ. Interleukin-1 beta contributes to the generation of experimental febrile seizures. Ann Neurol. 2005;57:152-5.

13. Vezzani A, Moneta D, Richichi C, Aliprandi M, Burrows SJ, Ravizza T, Perego C, De Simoni MG. Functional role of inflammatory cytokines and antiinflammatory molecules in seizures and epileptogenesis. Epilepsia. 2002; 43:30-5.

14. Lehtimaki KA, Peltola J, Koskikallio E, Keranen T, Honkaniemi J. Expression of cytokines and cytokine receptors in the rat brain after kainic acid-induced seizures. Mol Brain Res. 2003;110:253-60.

15. Rosell DR, Nacher J, Akama KT, McEwen BS. Spatiotemporal distribution of gp130 cytokines and their receptors after status epilepticus: comparison with neuronal degeneration and microglial activation. Neuroscience. 2003;122:329-48.

16. Cavalheiro EA, Fernandes MJ, Turski L, Naffah-Mazzacoratti MG. Spontaneous recurrent seizures in rats: amino acid and monoamine determination in the hippocampus. Epilepsia. 1994;35:1-11. 
17. Freitas RM, Viana GSB, Fonteles MMF. Striatal monoamines levels during status epilepticus. Rev Psiq Clin. 2003;30:76-9.

18. Khan GM, Smolders I, Ebinger G, Michotte Y. Anticonvulsant effect and neurotransmitter modulation of focal and systemic 2-chloroadenosine against the development of pilocarpine-induced seizure. Neuropharmacology. 2000;39:2418-32.

19. Meldrum B, Garthwaite J. Excitatory amino acid neurotoxicity and neurodegenerative disease. Trends Pharmacol Sci. 1990;11:379-87.

20. Freitas RM, CF FS, SMM V, GSB V, MMF F. Pilocarpine-induced seizures in adult rats: monoamine content and muscarinic and dopaminergic receptor changes in the striatum. Comp Biochem Physiol C Pharmacol Toxicol Endocrinol. 2003;136:103-8.

21. Turski L, Ikonomidou C, Turski WA, Bortolotto ZA, Cavalheiro EA. Cholinergic mechanisms and epileptogenesis. The seizures induced by pilocarpine: a novel experimental model of intractable epilepsy. Synapse. 1989;3:154-71.

22. Mercola R. Frankincense oil: the 'King' of oils; 2016.

23. Jalili C, Salahshoor M, Pourmotabbed A, Moradi S, Roshankhah SH Darehdori AS, Motaghi M. The effects of aqueous extract of Boswellia serrata on hippocampal region CA1 and learning deficit in kindled rats. Res Pharm Sci. 2014;9:351-8.

24. Moein P, Abbasi Fard S, Asnaashari A, Baratian H, Barekatain M, Tavakoli N, Moein $\mathrm{H}$. The effect of Boswellia serrata on neurorecovery following diffuse axonal injury. Brain Inj. 2013;27:1454-60.

25. Duncan JS, Sander JW, Sisodiya SM, Walker MC. Adult epilepsy. Lancet. 2006; 367:1087-100.

26. Chen JW, Naylor DE, Wasterlain CG. Advances in the pathophysiology of status epilepticus. Acta Neurol Scand Suppl. 2007;186:7-15.

27. Turski WA, Cavalheiro EA, Schwarz M, Czuczwar SJ, Kleinrok Z, Turski L. Limbic seizures produced by pilocarpine in rats: behavioural, electroencephalographic and neuropathological study. Behav Brain Res. 1983;9:315-35

28. Williams MB, Jope RS. Protein synthesis inhibitors attenuate seizures induced in rats by lithium plus pilocarpine. Exp Neurol. 1994;129:169-73.

29. Dal-Pizzol F, Klamt F, Vianna MM, Schröder N, Quevedo J, Benfato MS, Moreira JC, Walz R. Lipid peroxidation in hippocampus early and late after status epilepticus induced by pilocarpine or kainic acid in Wistar rats. Neurosci Lett. 2000;291:179-82.

30. Singh P, Chacko KM, Aggarwal ML, Bhat B, Khandal RK, Sultana S, Kuruvilla BT. A-90 Day gavage safety assessment of Boswellia serrata in rats. Toxicol Int. 2012;19:273-8.

31. Ruiz-Larrea MB, Leal AM, Liza M, Lacort M, de Groot H. Antioxidant effects of estradiol and 2-hydroxyestradiol on iron-induced lipid peroxidation of rat liver microsomes. Steroids. 1994;59:383-8.

32. Montgomery HAC, Dymock JF. The determination of nitrite in water. Analyst. 1961;86:414-6.

33. Beutler E, Duron O, Kelly BM. Improved method for the determination of blood glutathione. J Lab Clin Med. 1963:61:882-8.

34. Ellman GL, Courtney KD, Andres V. Featherstone RM (1961) a new and rapid colorimetric determination of acetylcholinesterase activity. Biochem Pharmacol. 1961;7:88-95.

35. Gorun V, Proinov I, Baltescu V, Balaban G, Barzu O. Modified Ellman procedure for assay of cholinesterase in crude-enzymatic preparations. Anal Biochem. 1978:86:324-6.

36. Ciarlone AE. Further modification of a fluoromertric method for analyzing brain amines. Microchem J. 1978;23:9-12.

37. Al-Yasiry AR, Kiczorowska B. Frankincense-therapeutic properties. Postepy Hig Med Dosw (Online). 2016;70:380-91.

38. Tomé AR, Ferreira PMP, Freitas RM. Inhibitory action of antioxidants (ascorbic acid or alfa-tocopherol) on seizures and bran damage induced by pilocarpine in rats. Arq Neuropsiquiatr. 2010;68:355-61.

39. Azam F, Prasad MV, Thangavel N. Targeting oxidative stress component in the therapeutics of epilepsy. Curr Top Med Chem. 2012;12:994-1007.

40. Draper $\mathrm{HH}$, Hadley M. Malondialdehyde determination as index of lipid peroxidation. Methods Enzymol. 1990;186:421-31.

41. Wasterlain CG, Fujikawa DG, Penix L, Sankar R. Pathophysiological mechanisms of brain damage from status epilepticus. Epilepsia. 1993;34:37-53.

42. Cavus I, Kasoff WS, Cassaday MP, Jacob R, Gueorguieva R, Sherwin RS, Krystal JH, Spencer DD, Abi-Saab WM. Extracellular metabolites in the cortex and hippocampus of epileptic patients. Ann Neurol. 2005;57:226-35.

43. Dar NJ, Bhat JA, Satti NK, Sharma PR, Hamid A, Ahmad M. Withanone, an active constituent from withania somnifera, affords protection against
NMDA-induced excitotoxicity in neuron-like cells. Mol Neurobiol. 2017;54: 5061-73.

44. Gonda X. Basic pharmacology of NMDA receptors. Curr Pharm Des. 2012;18: 1558-67.

45. Freitas RM, Souza FCF, Vasconcelos SMM, Viana GSB, Fonteles MMF. Oxidative stress in the hippocampus after status epilepticus in rats. FEBS J. 2005;272:1307-12.

46. Gupta RC, Dettbarn WD. Prevention of kainic acid seizures-induced changes in levels of nitric oxide and high-energy phosphates by 7-nitroindazole in rat brain regions. Brain Res. 2003;981:184-92.

47. Kato N, Sato S, Yokoyama H, Kayama T, Yoshimura T. Sequential changes of nitric oxide levels in the temporal lobes of kainic acid-treated mice following application of nitric oxide synthase inhibitors and phenobarbital. Epilepsy Res. 2005;65:81-91.

48. Maczurek A, Hager J, Kenklies M, Sharman M, Martins R, Engel J, Carlson DA, Munch G. Lipoic acid as an anti-inflammatory and neuroprotective treatment for Alzheimer's disease. Adv Drug Deliv Rev. 2008:60:1463-70.

49. Michiels C, Raes M, Toussaint O, Remacle J. Importance of seglutathione peroxidase, catalase, and cu /Zn-SOD for cell survival against oxidative stress. Free Radic Biol Med. 1994;17:235-48.

50. de Vasconcelos AP, Bouilleret V, Riban V, Wasterlain C, Nehlig A. Role of nitric oxide in cerebral blood flow changes during kainate seizures in mice: genetic and pharmacological approAchEs. Neurobiol Dis. 2005;18:270-81.

51. Kanemoto K, Kawasaki J, Yuasa S, Kumaki T, Tomohiro O, Kaji R, Nishimura M. Increased frequency of interleukin-1 beta-511T allele in patients with temporal lobe epilepsy, hippocampal sclerosis, and prolonged febrile convulsion. Epilepsia. 2003:44:796-9.

52. Vezzani A, Viviani B. Neuromodulatory properties of inflammatory cytokines and their impact on neuronal excitability. Neuropharmacology. 2015;96:70-82.

53. Janigro D, Iffland PHII, Marchi N, Granata T. A role for inflammation in status epilepticus is revealed by a review of current therapeutic approAchEs. Epilepsia. 2013:54:30-2

54. Lai AY, Swayze RD, El-Husseini A, Song C. Interleukin-1 beta modulates AMPA receptor expression and phosphorylation in hippocampal neurons. J Neuroimmunol. 2006;175:97-106.

55. Yang S, Liu ZW, Wen L, Qiao HF, Zhou WX, Zhang YX. Interleu-kin-1 beta enhances NMDA receptor-mediated current but inhibits excitatory synaptic transmission. Brain Res. 2005;1034:172-9.

56. Wang S, Cheng Q, Malik S, Yang J. Interleukin-1 beta inhibits gammaaminobutyric acid type a (GABA(a)) receptor current in cultured hippocampal neurons. J Pharmacol Exp Ther. 2000;292:497-504.

57. Srivastava A, Dixit AB, Banerjee J, Tripathi M, Sarat Chandra P. Role of inflammation and its mRNA based regulation in epilepsy: implications for therapy. Clin Chim Acta. 2016;452:1-9.

58. Jope RS, Simonato M, Lally K. Acetylcholine content in rat brain is elevated by status epilepticus induced by lithium and pilocarpine. J Neurochem. 1987:49:944-51.

59. Hillert MH, Imran I, Zimmermann M, Lau H, Weinfurter S, Klein J. Dynamics of hippocampal acetylcholine release during lithiumpilocarpine-induced status epilepticus in rats. J Neurochem. 2014;131: 42-52.

60. BozziY BE. The role of dopamine signaling in epileptogenesis. Front Cell Neurosci. 2013:7:157. https://doi.org/10.3389/fncel.2013.00157.

61. Giorgi FS, Pizzanelli C, Biagioni F, Murri L, Fornai F. The role of norepinephrine in epilepsy: from the bench to the bedside. Neurosci Biobehav Rev. 2004;28:507-24.

62. Bagdy G, Kecskemeti V, Riba P, Jakus R. Serotonin and epilepsy. J Neurochem. 2007;100:857-73.

63. Bhowmik $M$, Khanam $\mathrm{R}$, Vohora D. Histamine $\mathrm{H} 3$ receptor antagonists in relation to epilepsy and neurodegeneration: asystemic consideration of recent progress and perspectives. Br J Pharmacol. 2012;167:1398-414.

64. Siddiqui A, Mallajosyula JK, Rane A, Andersen JK. Ability to delay neuropathological events associated with astrocytic MAO-B increase in a Parkinsonian mouse model: implications for early intervention on disease progression. Neurobiol Dis. 2011;43:527-32.

65. Swathi G, Bhuvaneswar C, Rajendra W. Alterations of cholinergic neurotransmission in rotenone induced parkinson's disease: protective role of bacopa monnieri. Int J Pharm Bio Sci. 2013:3:286-92.

66. Aosaki T, Miura M, Suzuki T, Nishimura K, Masuda M. Acetylcholinedopamine balance hypothesis in the striatum: an update. Geriatr Gerontol Int. 2010;10:S148-57. 
67. Villa NR, Pacheco-Hernández Y, Becerra-Martínez E, Zárate-Reyes JA, Cruz-Duráne R. Chemical profile and pharmacological effects of the resin and essential oil from Bursera slechtendalii: a medicinal "copal tree" of southern Mexico. Fitoterapia. 2018;128:86-92.

68. Brenes A, Roura E. Essential oils in poultry nutrition: Main effects and modes of action. Anim Feed Sci Technol. 2010;158:1-14.

69. Zeng Z, Zhang S, Wang H, Piao X. Essential oil and aromatic plants as feed additives in non-ruminant nutrition: a review. J Anim Sci Biotechnol. 2015;6:7. https://doi.org/10.1186/s40104-015-0004-5 eCollection 2015

70. García DA, Bujons J, Vale C, Suñol C. Allosteric positive interaction of thymol with the GABAA receptor in primary cultures of mouse cortical neurons. Neuropharmacology. 2006;50:25-35.

71. Delgado-Marín L, Sánchez-Borzone M, García DA. Neuroprotective effects of gabaergic phenols correlated with their pharmacological and antioxidant properties. Life Sci. 2017;175:11-5.

72. Wojdylo A, Oszmianski J, Czemerys R. Antioxidant activity and phenolic compounds in 32 selected herbs. Food Chem. 2007;105:940-9.

73. Haeseler G, Maue D, Grosskreutz J, Bufler J, Nentwig B, Piepenbrock S, Dengler R, Leuwer M. Voltage-dependent block of neuronal and skeletal muscle sodium channels by thymol and menthol. Eur J Anaesthesiol. 2002;19:571-9.

74. Priestley CM, Williamson EM, Wafford KA, Sattelle DB. Thymol, a constituent of thyme essential oil, is a positive allosteric modulator of human GABAA receptors and a homo-oligomeric GABA receptor from Drosophila melanogaster. Br J Pharmacol. 2003;140:1363-72.

75. Sancheti J, Shaikh MF, Chaudhari R, Somani G, Patil S, Jain P, Sathaye S. Characterization of anticonvulsant and antiepileptogenic potential of thymol in various experimental models. Naunyn Schmiedeberg's Arch Pharmacol. 2014;387:59-66.

76. Aeschbach R, Loliger J, Scott BC, Murcia A, Butler J, Halliwell M, Aruoma Ol. Antioxidant actions of thymol, carvacrol, 6-gingerol, zingerone and hydroxytyrosol. Food Chem Toxicol. 1994;32:31-6.

77. Javed H, Azimullah S, Meeran MFN, Ansari SA, Ojha S. Neuroprotective effects of Thymol, a dietary Monoterpene against dopaminergic Neurodegeneration in rotenone-induced rat model of Parkinson's disease. Int J Mol Sci. 2019;20:1538 https://doi.org/10.3390/ijms20071538.

78. Mander P, Brown GC. Activation of microglial NADPH oxidase is synergistic with glial iNOS expression in inducing neuronal death: a dual-key mechanism of inflammatory neurodegeneration. J Neuroinflammation. 2005;2:20.

79. Sokmen A, Sokmen M, Daferera D, Polissiou M, Candan F, Unlu M, Akpulat HA. The in vitro antioxidant and antimicrobial activities of the essential oil and methanol extracts of Achillea biebersteini Afan. (Asteraceae). Phytother Res. 2004;18:451-6.

80. Khalil A, Kovac S, Morris G, Walker MC. Carvacrol after status epilepticus (SE) prevents recurrent $\mathrm{SE}$, early seizures, cell death, and cognitive decline. Epilepsia. 2017;58:263-73.

81. Guimarães AG, Xavier MA, de Santana MT, Camargo EA, Santos CA, Brito FA, Barreto EO, Cavalcanti SC, Antoniolli AR, Oliveira RC, Quintans-Júnior LJ. Carvacrol attenuates mechanical hypernociception and inflammatory response. Naunyn Schmiedeberg's Arch Pharmacol. 2012;385:253-63.

82. Hotta M, Nakata R, Katsukawa M, Hori K, Takahashi S, Inoue H. Carvacrol, a component of thyme oil, activates PPAR alpha and gamma, and suppresses COX-2 expression. J Lipid Res. 2010;51:132-9.

83. Crofford LJ, Wilder RL, Ristimaki AP, Sano H, Remmers EF, Epps HR, Hla T. Cyclooxygenase-1 and -2 expression in rheumatoid synovial tissues. Effects of interleukin-1 beta, phorbol ester, and corticosteroids. J Clin Invest. 1994; 93:1095-101.

84. Markesbery WR. Oxidative stress hypothesis in Alzheimer's disease. Free Radic Biol Med. 1997;23:134-47.

85. Jukic M, Politeo O, Maksimovic M, Milos M, Milos M. In vitro acetylcholinesterase inhibitory properties of thymol, carvacrol and their derivatives thymoquinone and thymohydroquinone. Phytother Res. 2007;21:259-61.

86. Gajda Z, Szupera Z, Blazsó G, Szente M. Quinine, a blocker of neuronal cx36 channels, suppresses seizure activity in rat neocortex in vivo. Epilepsia. 2005;46:1581-91.

87. Bostanci MO, Bağirici F. The effects of octanol on penicillin induced epileptiform activity in rats: an in vivo study. Epilepsy Res. 2006;71: 188-94.
88. de Oliveira TM, de Carvalho RB, da Costa $I H$, de Oliveira GA, de Souza AA, de Lima SG, de Freitas RM. Evaluation of p-cymene, a natural antioxidant. Pharm Biol. 2015;53:423-8.

89. Moss M, Oliver L. Plasma 1,8-cineole correlates with cognitive performance following exposure to rosemary essential oil aroma. Ther Adv Psychopharmacol. 2012;2:103-13.

\section{Publisher's Note}

Springer Nature remains neutral with regard to jurisdictional claims in published maps and institutional affiliations.

\section{Submit your manuscript to a SpringerOpen ${ }^{\circ}$ journal and benefit from:}

- Convenient online submission

- Rigorous peer review

- Open access: articles freely available online

- High visibility within the field

- Retaining the copyright to your article

Submit your next manuscript at $\boldsymbol{\nabla}$ springeropen.com 